\title{
Meta-analysis of randomised trials compares mortality after transcatheter versus surgical aortic valve replacement
}

\author{
J. Vendrik $\cdot$ J. Baan Jr.
}

Published online: 17 April 2020

(C) The Author(s) 2020

In this issue of the Netherlands Heart Journal, Takagi et al. [1] report a systematic review and meta-analysis regarding the treatment of patients with severe symptomatic aortic stenosis, with either a transcatheter (transcatheter aortic valve implantation, TAVI) or fully surgical (surgical aortic valve replacement, SAVR) approach. Their study provides us with a very thorough update on mortality after both procedures, using data gathered from all of the pivotal randomised trials [2-8]. Although none of the original analyses and current meta-analyses from the individual trials reported significantly lower mortality after TAVI than after SAVR, their pooled analyses of 7631 patients, including the most recent low-risk trials [3, 5], did show a significantly lower mortality associated with TAVI. The absolute risk reduction with TAVI is small, $0.6 \%$ and $1.1 \%$ for 30 -day and 1 -year mortality, respectively. However, when combined with the fact that absolute mortality rates are already very low in current day practice, in addition to the ongoing increase in the number of TAVI procedures performed in the Netherlands [9], even these relatively small reductions may be of clinical significance. Hence, this article supports the ongoing broadening indication for TAVI and the gradual shift toward TAVI becoming the preferred treatment strategy in the majority of patients with severe symptomatic aortic stenosis. However, a few caveats in the current literature and in our knowledge still remain, the most prominent being long-term valve durability. Since the studies included in this systematic review, as the authors properly acknowledge, do not report on long-term follow-up, no conclusions can be drawn regarding long-term valve

J. Vendrik $(\bowtie) \cdot$ J. Baan Jr.

Heart Centre, Amsterdam University Medical Centres

(location AMC), Amsterdam, The Netherlands

j.vendrik@amsterdamumc.nl durability. All known data in high-risk and inoperable patients show acceptable and, more importantly, similar or lower rates of structural valve deterioration (SVD) in TAVI-treated patients than in SAVR-treated patients [10]. To date, results of long-term follow-up in low-risk patients are available only from the NOTION trial [11], showing a lower 6-year rate of SVD in transcatheter valves than in surgical aortic bioprostheses $(4.8 \%$ vs $24 \%$; $p<0.001)$. However, in this trial earlier-generation prostheses (both transcatheter and surgical) were implanted, and newer prostheses may yield different, better long-term results. In vitro testing of the latest SAPIEN 3 aortic prosthesis showed excellent results up to the equivalent of 25 years in nominally expanded valves, comparable with the newest surgically implanted prostheses [12]. Since the PARTNER 3 [3] and Evolut R Low Risk [5] trials will provide us with much awaited long-term echocardiographic data on low-risk patients treated with the newest prostheses, patience is required in this regard.

This, however, raises the next caveat in our knowledge. In the most recent low-risk trials, patients were treated only via a transfemoral approach $(100 \%$ for the PARTNER-3 [3] and 99\% for the Evolut Low Risk RCT [5] respectively). Hence no conclusions can be drawn regarding TAVI using different access routes. As a large proportion of the screened patients $(302 / 1435)$ in the PARTNER 3 trial were not included due to anatomical exclusion criteria, the subgroup of patients who cannot undergo transfemoral (TF-) TAVI can be substantial [3]. Since alternative access routes are per definition more invasive than TF-TAVI, and often reflect a worse preoperative patient health status, extrapolation of these data to other subgroups of patients, and comparing these to those of surgically treated patients, can only be done with extreme caution.

Thirdly, one of the most prominent TAVI-related complications is the need for permanent pacemaker 
implantation (NPPMI). Takagi et al. describe a risk difference of $+8.89 \%$ for NPPMI at 30 days for the TAVI-treated patients. Pacemaker implantation does not influence short- and mid-term mortality $[1,13$, 14], but may negatively influence long-term mortality in theory, especially in completely pacemaker-dependent patients. The need for NPPMI is highly dependent on the valve system used. As reported in both the simultaneously published low-risk trials, which showed $17.4 \%$ [5] and $6.6 \%$ [3] for the TAVI patients in the Evolut Low-Risk and PARTNER 3 trials, respectively, as well as in large, pooled analyses [15], NPPMI rates are substantially higher when self-expandable valves are used. In the PARTNER 3 trial, the NPPMI rate was not significantly higher in the TAVI-treated than in the SAVR-treated patients (6.6\% vs $4.1 \%)$. As younger and healthier, lower-risk patients are treated, with fewer risk factors for NPPMI [16], and as implantation techniques evolve $[17,18]$ and algorithms are created, avoiding futile pacemaker implantation [19], NPPMI rates may decrease further until they reach the SAVR range.

Lastly, although post-procedural mortality is the most important and hard endpoint, it is not the only one. Especially for the population of fragile, elderly patients, softer endpoints such as a short period of hospitalisation, quick recovery, symptomatic improvement and quality of life may be just as important. In the PARTNER 3 data, the median length of hospitalisation was 3 days after TAVI, and 7 days after SAVR. Furthermore, a significantly larger proportion of the TAVI-treated patients were discharged to their own home $(95.8 \%$ vs $73.1 \%)$. Several earlydischarge protocols have been published (FAST-TAVI [20], 3M-TAVR [21]) to further facilitate short hospital stays and possibly quicker recovery [22, 23]. In this regard, the PARTNER 3 data show us that 30 days after the procedure only $19.7 \%$ of the TAVI-treated patients had dyspnoea (New York Heart Association class $\geq 2$, versus $33.3 \%$ in the SAVR group), whereas TAVI-treated patients walked $32 \%$ further during the 6 -min walk test and scored $38 \%$ better on the Kansas City Cardiomyopathy Questionnaire score. All these outcomes are similar for both approaches at 1-year follow-up, depicting a quicker recovery for TAVItreated patients. Although all these findings need to be further confirmed with real-life data, they do support the evidence that the treatment paradigm is justly shifting towards TAVI.

In conclusion, Takagi et al. provide us with a much appreciated systematic review, guiding current treatment of patients with aortic valve stenosis. Several challenges need to be overcome in the future. However, current data reflect significant benefits for TAVI over SAVR in the majority of patients with severe symptomatic aortic valve stenosis.
Conflict of interest J. Baan Jr. receives an unrestricted research grant from Edwards Lifesciences. J. Vendrik declares that he has no competing interests.

Open Access This article is licensed under a Creative Commons Attribution 4.0 International License, which permits use, sharing, adaptation, distribution and reproduction in any medium or format, as long as you give appropriate credit to the original author(s) and the source, provide a link to the Creative Commons licence, and indicate if changes were made. The images or other third party material in this article are included in the article's Creative Commons licence, unless indicated otherwise in a credit line to the material. If material is not included in the article's Creative Commons licence and your intended use is not permitted by statutory regulation or exceeds the permitted use, you will need to obtain permission directly from the copyright holder. To view a copy of this licence, visit http://creativecommons.org/licenses/by/4.0/.

\section{References}

1. Takagi H, Hari Y, Nakashima K, Kuno T, Ando T, ALICE (AllLiteratureInvestigation ofCardiovascular Evidence) Group. Mortality after transcatheter versus surgical aortic valve replacement: an updated meta-analysis of randomised trials. Neth Heart J. 2020; https:// doi.org/10.1007/s12471020-01378-1.

2. Leon MB, Smith CR, Mack MJ, Makkar RR, Svensson LG, Kodali SK, et al. Transcatheter or surgical aortic-valve replacement in intermediate-risk patients. N Engl J Med. 2016;374(17):1609-20.

3. Mack MJ, Leon MB, Thourani VH, Makkar R, Kodali SK, Russo M, etal. Transcatheter aortic-valve replacement with a balloon-expandable valve in low-risk patients. N Engl J Med. 2019;380:1695-705.

4. Reardon MJ, Van Mieghem NM, PopmaJJ, Kleiman NS, Sondergaard L, Mumtaz M, et al. Surgical or transcatheter aortic-valve replacement in intermediate-risk patients. NEngl JMed. 2017;376:1321-31.

5. Popma JJ, Deeb GM, Yakubov SJ, Mumtaz M, Gada H, O'Hair D, etal. Transcatheter aortic-valve replacement with a self-expanding valve in low-risk patients. N Engl J Med. 2019;380:1706-15.

6. Thyregod HG, Steinbruchel DA, Ihlemann N, Nissen H, Kjeldsen BJ, Petursson P, et al. Transcatheter versus surgical aortic valve replacement in patients with severe aortic valve stenosis: 1-year results from the all-comers NOTION randomized clinical trial. J Am Coll Cardiol. 2015;65(20):2184-94.

7. Smith CR, Leon MB, Mack MJ, Miller DC, Moses JW, Svensson LG, et al. Transcatheter versus surgical aorticvalve replacement in high-risk patients. $\mathrm{N}$ Engl J Med. 2011;364(23):2187-98.

8. Adams DH, Popma JJ, Reardon MJ, Yakubov SJ, Coselli JS, Deeb GM, et al. Transcatheter aortic-valve replacement with a self-expanding prosthesis. N Engl J Med. 2014;370(19):1790-8.

9. NHR registratie. Nederlandse Hart Registratie (NHR)e 2019. https://nederlandsehartregistratie.nl/wp-content/ uploads/2020/01/NHR-Rapportage-2019-per-spread230120.pdf. Accessed 2019

10. Ielasi A, Latib A, Tespili M, Donatelli F. Current results and remaining challenges of trans-catheter aortic valve replacement expansion in intermediate and low risk patients. Int J Cardiol Heart Vasc. 2019;23:100375.

11. Thyregod HGH, Ihlemann N, Jorgensen TH, Nissen H, Kjeldsen BJ, Petursson P, et al. Five-year clinical and 
echocardiographic outcomes from the nordic aortic valve intervention (NOTION) randomized clinical trial in lower surgical risk patients. Circulation. 2019;139:2714-23.

12. Sathananthan J, Hensey M, Landes U, Alkhodair A, Saidud$\operatorname{din}$ A, Sellers S, et al. Long-term durability of transcatheter heart valves: insights from bench testing to 25 years. JACC Cardiovasc Interv. 2020;13(2):235-49.

13. Giustino G, Van der Boon RM, Molina-Martin de Nicolas J, Dumonteil N, Chieffo A, de Jaegere PP, et al. Impact of permanent pacemaker on mortality after transcatheter aortic valve implantation: the PRAGMATIC (Pooled RotterdamMilan-Toulouse in Collaboration) pacemaker substudy. EuroIntervention. 2016;12(9):1185-93.

14. Ueshima D, Nai Fovino L, Mojoli M, Napodano M, Fraccaro C, Tarantini G. The interplay between permanent pacemaker implantation and mortality in patients treated by transcatheter aortic valve implantation: a systematic review and meta-analysis. Catheter Cardiovasc Interv. 2018;92(3):E159-E67.

15. Vlastra W, Chandrasekhar J, Munoz-Garcia AJ, Tchetche D, de Brito FS Jr., Barbanti M, et al. Comparison of balloon-expandablevs. self-expandable valves in patients undergoing transfemoral transcatheter aortic valve implantation: from the CENTER-collaboration. Eur Heart J. 2019;40(5):456-65.

16. Franzone A, Windecker S. The conundrum of permanent pacemaker implantation after transcatheter aortic valve implantation. Circ Cardiovasc Interv. 2017;10(7):e005514. https://www.ncbi.nlm.nih.gov/pubmed/28698293

17. Rodriguez-Olivares R, Nijhoff F, Stella PR. Conduction abnormalities and pacemaker implantations after SAPIEN
3 Vs SAPIEN XT: depending on who is implanted and how you implant. RevEsp Cardiol. 2016;69(4):455.

18. Schwerg M, Fulde F, Dreger H, Poller WC, Stangl K, Laule M. Optimized implantation height of the Edwards SAPIEN 3 valve to minimize pacemaker implantation after TAVI. J Interv Cardiol. 2016;29(4):370-4.

19. Costa G, Zappulla P, Barbanti M, Cirasa A, Todaro D, Rapisarda G, et al. Pacemaker dependency after transcatheter aortic valve implantation: incidence, predictors and longterm outcomes. EuroIntervention. 2019;15(10):875-83.

20. Barbanti M, van Mourik MS, Spence MS, Iacovelli F, Martinelli GL, Muir DF, et al. Optimising patient discharge management after transfemoral transcatheter aortic valve implantation: the multicentre European FAST-TAVI trial. EuroIntervention. 2019;15(2):147-54.

21. Wood DA, Lauck SB, Cairns JA, Humphries KH, Cook R, Welsh R, et al. The Vancouver 3M (multidisciplinary, multimodality, but minimalist) clinical pathway facilitates safe next-day discharge home at low-, medium-, and high-volume transfemoral transcatheter aortic valve replacement centers: the 3M TAVR study. JACC Cardiovasc Interv. 2019;12(5):459-69.

22. Kotronias RA. Early vs standard discharge after transcatheter aortic valve implantation: a systematic review and meta-analysis. JACC Cardiovasc Interv. 2018; 11(17):1759-71.

23. Baan J Jr., Vendrik J. The sooner the better?: The doctor knows best. JACC Cardiovasc Interv. 2018;11(17):1772-4. 